\title{
Imágenes del exceso. El neobarroco como forma "invisible" del neoliberalismo político y cultural. Argentina 1990-2000
}

\section{Images of excess The neo-baroque as an "invisible" form of political and cultural neoliberalism. Argentina 1990-2000}

Tipo de trabajo: comunicación.

PALABRAS CLAVES

Artes visuales-Argentina-Neobarroco-Neoliberalismo.

KEY WORDS

Visual arts-Argentina-Neo-Baroque-Neoliberalism.

RESUMEN

En los últimos años del S.XX la Argentina se encuentra gobernada bajo los ideales del neoliberalismo económico y político. Desde las artes visuales los artistas se manifiestan con nuevas formas estéticas ligándose con jóvenes instituciones. Crean producciones simbólicas que reflexionan sobre el mundo expuesto a la proliferación y al poder de las imágenes; con una mirada sagaz discuten la historia. Englobados en distintos estilos analizaremos las obras de Marcos López, Marcelo Pombo, Omar Schirillo, Alejandro Kuroptawa, Lliana Maresca y Feliciano Centurión. Discutiremos la mirada de la crítica del período y el uso de los términos de Light, kitsch, Guarango y Diet para definir sus obras. Proponemos cruces y relaciones con la pervivencia del concepto de neobarroco, planteando que los artistas utilizaron distintas estrategias para develar una crítica despiadada a la idiosincracia de la sociedad de la época.

\section{ABSTRACT}

In the last years of the 20th Century, Argentina is governed by the ideals of economic and political neoliberalism. The visual artists manifest with new aesthetic forms linking with young institutions. They create symbolic productions that reflect on the world exposed to the proliferation and power of images; With a shrewd look they discuss the history. Embedded in different styles, we will analyze the works of Marcos López, Marcelo Pombo, Omar Schirillo, Alejandro Kuroptawa, Lliana Maresca and Feliciano Centurión. We will discuss the critical view of the period and the use of the terms Light, kitsch, Guarango and Diet to define their works. We propose links and relationships with the survival of the neo-baroque concept, stating that artists used different strategies to unveil a ruthless criticism of the idiosyncrasies of the society of the time.

\section{INTRODUCCION}

Durante los últimos años del S.XX, la Argentina se encuentra gobernada bajo los ideales del neoliberalismo económico y político. Quizás con una mirada sesgada y desde una parte de la crítica y de la historia del arte se establece que un grupo de artistas que se manifiestan desde nuevas formas estéticas y se ligan con jóvenes instituciones, conforman una serie de producciones simbólicas que sino "adherían", "vehiculizaban" una imagen acorde a la ideología del poder.

Analizando estas producciones y su tiempo se pueden establecer cruces y relaciones con el concepto de neobarroco, por lo cual es posible plantear que los artistas trabajaron para, con y desde una imagen que se presenta adherida y consecuente con las problemáticas políticas, reflexionan sobre la exposición y proliferación de imágenes apelando a la saturación y al horror vacui, para develar a través de la parodia, la metáfora y la ironía una crítica despiadada a la idiosincracia de la sociedad. 
Las distintas maneras y formas de producir, por parte de los artistas estuvo en apariencia "determinada" por conceptos como Light (López Anaya,1992)Anaya, guarango (Restany,1995), diet o desideologizado. Se asociaron sus prácticas artísticas al momento político. En un análisis un poco rápido se categorizaron sus obras como: kitsh, de bajo costo y de factura rápida.

Se volvió a discutir la histórica división entre forma y contenido ${ }^{1}$ en una obra de arte, acusando a este grupo de artistas de realizar objetos desvinculados de lo social e histórico.

El período analizado se desarrolla bajo el gobierno de Carlos Menem (1989-1999), quine implementa un modelo de privatizaciones y liberación de las importaciones que paraliza la industria nacional y conduce a marcadas desventajas laborales, pauperizando las condiciones de trabajo y provocando un nivel muy alto de desempleo y de desigualdad social. acarreando un fuerte endeudamiento externo.

Desde el campo cultural el Centro C. Recoleta, el Instituto de Cooperación Iberoamericana ICI, el MAMBA, el Casal de Cataluña, la Fundación Banco Patricios o la Fundación Espigas desarrollaron sus actividades junto a nuevas formas de capacitación y compusieron un panorama que acompañó a los distintos artistas en su trabajo. En medios como El Porteño, El periodista, La Maga, Pagina 12, Humor, Sex humor, Cerdo y Peces o Ramona se publicaron las crónicas de este período.

Si queremos describir de una forma general lo que acontecía por esos tiempos en las formas plásticas, encontramos conviviendo distintos estilos tales como el neo geo, neo minimal, neo conceptual, neo barroco o neo pop, que se hibridan en los mas variados artistas y éstos pueden pasar de una a otra poética sin prejuicios.

Los trabajos que se han realizado sobre el período aún no completan totalmente el espectro de lo sucedido. Debemos considerar como antecedentes y fuentes los estudios realizados en el período por Jorge López Anaya; Pierre Restany; Jorge Gumier Maier; Fabián Lebenglik y Laura Batkis quienes escribieron desde los medios de comunicación y realizaron curadurías y prólogos para distintas exposiciones, así como un poco mas recientemente las investigaciones y críticas realizadas por Adriana Lauria; Andrea Giunta; Valeria González; Máximo Jacoby; Inés Katzenstein; Fernando Farina; Marcelo Pacheco y Claudio Iglesias entre otros, que han sido citados en nuestro trabajo como una parte importante del estado de la cuestión.

\section{METODOLOGIA}

En nuestro caso de estudio trabajamos desde una perspectiva comparada entre modelos teóricos, planteando un enfoque multidisciplinar, que nos permite a través del análisis icnográfico y hermenéutico de una serie de obras y fuentes, proponer una ampliación al debate del período desde la historia del arte.

\section{DESARROLLO}

El panorama es complejo y diverso no excepto de contradicciones y se construye a través de una multiplicidad de artistas y obras.

Alrededor de 1989 convocan las autoridades de C.C.Rojas ${ }^{2}$ a Jorge Gumier Maier ${ }^{3}$, para que tome el cargo de curador de la sala de exposición de artes plásticas, -en ese entonces contaba simplemente con un pasillo entre salas que funcionaba como la galería- quien pensó este espacio como ex-céntrico para dar lugar a jóvenes artistas fuera del Establishment.

Organiza la programación del lugar e invita a inaugurarlo a Liliana Maresca, quien presenta una video instalación denominada "Lo que el viento se llevo". La imágenes filmadas se centran en la muerte de un modelo idílico de sociedad, poniendo en primer plano un paseo del tigre, icono del lugar de esparcimiento de la clase media, que luego de una tormenta está completamente destruido y abandonado.

\footnotetext{
${ }^{1}$ En el Centro Cultural Rojas, en junio de 1993 organiza Marcia Schvartz, Felipe Pino y Duilio Pierri las jornadas sobre las características del "arte light", En el 2003 en el Malba se realizará "Arte Light-arte Rosa Luxemburgo". Ver "Arte rosa Light y arte Rosa Luxemburgo" en Ramona, Buenos Aires, nro 33,julio/agosto 2003, pp.52-91 en línea : http://www.ramona.org.ar/files/r33.pdf

2 El Centro Cultural fue creado en 1984, como organismo dependiente de la UBA, dirigido entre 1986 y 1993 por Leopoldo Sosa Pujato. Para profundizar ver Calzón Flores (Ed) 25 años del Rojas, Buenos Aires, Libro del Rojas, 2009.

${ }^{3}$ Durante 1991 se suma Magdalena Jitrik a la tarea curatorial y Gumier Maier estará hasta 2003 con algunas ausencias y cierres. En 1995 se crea la foto galería curada por Alberto Goldestein.
} 
March, Natalia Laura

Imágenes del exceso. El neobarroco como forma "invisible" del neoliberalismo político y cultural. Argentina 1990-2000

IV Congreso INTERNACIONAL DE INVESTIGACION EN ARTES VISUALES ANIAV 2019

IMAGEN [N] VISIBLE

http://dx.doi.org/10.4995/ANIAV.2019.9586

A partir de allí se suscitarán una serie de exposiciones y con el paso del tiempo se comienza a delimitar a un grupo de pertenencia que serán Ilamados "El grupo del Rojas": Marcelo Pombo, Omar Schirillo, Feliciano Centurion, Alejandro Kuropatwa, Miguel Harte, Emiliano Miliyo, Alfredo Londaibere, Fernanda Laguna, Benito Laren, Román Vitali y al propio Gumier Maier. ${ }^{4}$

El objeto ambiguo, el simulacro, la ironía y la parodia, serán estrategias desplegadas en variadas materialidades por estos artistas. El discurso de género, la multiplicidad de voces, sobre todo las acalladas e invisibles serán protagonistas desde distintas subjetividades.

Nos permitimos introducir aquí el concepto de "neobarroco" como factor que engloba lo anteriormente descripto y desde esta perspectiva es que proponemos releer el período. Abriendo la posibilidad de repensar las obras desde la manipulación y sobre exposición de imágenes.

Siguiendo a Omar Calabrese (1999:p.12) el autor aclara que hablar de neobarroco no es volver al barroco y que tampoco engloba todo lo que sucede en un tiempo presente, sino que lo plantea como un "aire de época", cuyas características serían la inestabilidad, la polidimensionalidad y la mutabilidad, en la sociedad contemporánea y que en nuestro caos se manifiestan dentro de una estética social.

Desde esta perspectiva retoma algunas de las formas de definición de Severo Sarduy (1987), considerando al barroco casi como una categoría del espíritu y mas allá de una larga disquisición sobre la pertinencia o no de retomar definiciones extra-históricas, propone buscar las marcas del neobarroco como algunas formas de la desestabilización contemporánea. ${ }^{5}$

En la misma tradición es que Bolivar Echeverría en su texto La clave barroca en América Latina escribe: "El ethos barroco, tan frecuentado en las sociedades latinoamericanas a lo largo de su historia, se caracteriza por su fidelidad a la dimensión cualitativa de la vida y su mundo y por su negativa a aceptar el sacrificio de ella"6.

Este autor plantea las diferentes formas de la sociedad y su relación con el capitalismo temprano y considera que en Latinoamérica luego de la conquista se establece esa relación a través de un "ethos barroco", recatado y desobediente, que a la vez que combina y mezcla elementos permite la transculturación.

Este punto de vista está en sintonía con pensadores como Alejo Carpentier, y José Lezama Lima, quienes vieron el barroco caribeño hispano-parlante como producto de la transculturización y como un estilo transgresivo no sólo de la colonialidad sino de la modernidad?

El ethos se define como la posibilidad de convivir con la modernidad capitalista, restableciendo las relaciones entre valor de uso y valor de cambio. Para el autor el barroco en particular, intenta salvar el valor de uso y es contradictorio sabiendo que el sistema capitalista hace imposible la felicidad pero igualmente trata de alcanzarla. Combina y mezcla elementos de forma caótica, transgrediendo y permitiendo el mestizaje.

Bolivar Echeverria, encuentra un intersticio en el "ethos barroco", le atribuye un poder liberador, si bien otros autores relativizan la división entre valor de cambio y valor de uso en la modernidad.8

Es por ello que nos resulta interesante esta posible forma de resistencia:

Tal vez lo que es revolución habrá que pensarlo ya no en clave romántica sino, por ejemplo, en clave barroca. No como la toma apoteótica del Palacio de Invierno, sino como la invasión rizomática, de violencia no militar, oculta y lenta pero omnipresente e imparable, de aquellos otros lugares, lejanos a veces del pretencioso escenario de la Política, en donde lo político --lo refundador de las formas de la socialidad-- se prolonga también y está presente dentro de la vida cotidiana" (Echeverria,2002:12).

Desde esta perspectiva creemos posible analizar los siguientes casos como formas de resistencia al momento neoliberal, explayando una critica profunda la idiosincracia argentina, como formas de transculturación, de hibridación y de liberación.

\footnotetext{
${ }^{4}$ Por las sala de exposición también van a pasar Pablo Suárez, Marcia Schvartz, Roberto Jacoby, Magdalena Jitrik, Beto de Volder, Pablo Siquier, Margarita Paksa, Diulio Pierri, Juan José Cambre, tulio de Sagastizabal, etc.

${ }^{5}$ Ver Sarti Graciela, “Neobarrocos del presente. Vigencia de una categoría estética”, Buenos Aires, Arte x Arte, 2017 y O.Calabrese, op. cit. pp.38-43.
}

7 Para profundizar ver Carlos Espinosa en "El barroco y Bolivar Echeverria: encuentros y desencuentros",en Íconos. Revista de Ciencias Sociales. Num. 43, Quito, mayo 2012, pp. 65-80 
El empleo de materiales extra-artísticos como palanganas, nylon, cuentas de vidrio, frazadas, tejidos, bordados, pintura sintética, resinas, objetos de plásticos, de bajo costo, adornos, envases de productos de consumo, peluches, papel crepé, con colores apastelados, brillantes y superficies pulidas, da cuenta de las referencias profundas a un bricolage deslucido y degradado.

Ines Katzenstein (2015:114-5) dice sobre Marcelo Pombo: "Cuando emprendió procedimientos de apropiación típicos del arte conceptual, lo hizo confundiéndolos, rebajándolos a través de procedimientos artesanales y decorativos" y continúa "Lo bello gestará monstruosidades, lo barroco será discreto, lo político será confuso y caprichoso"

Dentro de la producción del artista, su obra "Winco" (Figura1), se instalará a futuro como una de las "paradigmáticas" del período, en ésta aparece chorreado un equipo de música -tocadiscos- de pintura sintética, desfuncionalizado, con recortes de imágenes no azarosas y con el pastiche como argumento, para el caso de las piezas realizadas con los envases de bebidas -tetra brick de jugos de marca Cepita- le agrega piezas, mariposas, moñitos de papel, uvitas de plástico, aquí utiliza el exceso de lo decorativo y redundante, provocando un horror vacui, confundiendo así lo lindo, lo feo, lo popular.

Para el caso de "Navidad en San Francisco Solano" (Figura 2) trabaja acumulando restos de cartones de envases de objetos de consumo, y los salpica con gotitas de esmalte parodiando la navidad nevada y lo degrada más aún con los flequitos de nylon kitsch que rodean al marco. Con adornos baratos, donde la fiesta linda con la tragedia. Lo indivual se vuelve colectivo.

En el caso de Omar Schrilio sus obras "Palanganas" (Figura 3) se trasvisten de objetos preciosos, de valor, arañas, o caireles de cristal se conforman con plástico industrial. Marcelo Pacheco (2006:89) habla de un Ready-made invertido, desplaza el objeto de uso, y lo niega conceptualmente al embellecerlo y refuncionalizarlo, redoblando la condición de fetiche.

La saturación decorativista en una característica común, pero como una acción provocativa, camuflan, el neoliberalismo en su desbordante e imperiosa ley del consumo, poniendo en escena y enfatizando en lo banal e intrascendente. El material seleccionado no es ni neutro ni inocente.

En las fotografías de Marcos López el color saturado es marca, en "Carnaval criollo" de la serie Pop Latino (Figura 4) una mujer en la calle guantes de latex, y careta de estatua de la libertad, por detrás la publicidad de la Línea aérea American Airlines nos lleva a "New York sin escalas". En la etapa neoliberal la apertura económica y las relaciones carnales con el país del norte son vividas por una clase media en ascenso que podría llegar a "donde nunca pudo", en medio del hundimiento del país.

En "Santuario" (Figura 5) en primer plano una desbordada figura femenina entra en éxtasis, logra el milagro, con el producto de limpieza que saca brillo a los bronces, se ilumina la imagen devocional de pvc o yeso, en un santuario privado, hibridado de tradiciones y ejemplo del mejor de los pastiches social y cultural argentino.

Explica Claudio Iglesias (2015:147) "la devoción por materiales culturales y signos económicos desprestigiados, desvencijados o rotos es tan firme como la voluntad de limpiarlos, depurarlos o renovarlos."

La empatía que se da entre los artistas sus materiales y sus imágenes, en un complejo ideal de belleza, transmite la preocupación por el horizonte de expectativas que va teniendo nuestra comunidad.

Abordar y pensar el cuerpo como un espacio donde el tránsito de la vida deja variadas huellas: desde el exceso y el goce, desde la fiesta y el despilfarro, como desde el dolor es una de las características posibles que aglutina a un variado grupo de artistas.

La muerte individual, social y política que trae el SIDA, en los tiempos neoliberales exponen los cuerpos que se ocultaron y excluyeron. El cuerpo será entendido como una sexualidad disidente, desde donde se intenta desestabilizar las normativas vigentes. Habitar una piel, un cuerpo en un tiempo determinado.

Liliana Maresca realiza Wotan-Vulcano (Figura 6) una instalación con carcasas de zinc para féretros, alfombra persa, pintura dorada y farol a kerosene. Pedidas especialmente al cementerio llegaron sucias con restos. Tuvo que limpiarlos, quemándolos en la acción alquímica y transmutadora del fuego. La obra se expone con las paredes y el piso pintadas de dorado y ambientado en un tono rojizo. Dentro de los ataúdes se quemaban unas pilas de incienso. En plena guerra del Golfo Pérsico, residuos y muerte, la propia y la de los otros se presenta escenificada. Como la vanitas, haciendo foco en la transitoriedad de la vida humana.

Por el mismo camino Feliciano Centurión exhibe sus propia enfermedad, en "Me adapto" su finitud, en colchas bordadas con hilos de algodón, expone como fluyen aún los humores por su cuerpo, recupera las tradiciones sin perder lo sutil, lo inasible y lo bello. La palabra bordada expresa el dolor, la muerte y el HIV.(Figura 7).

La exposición de la problemática del SIDA en obra se da en varios artistas al mismo tiempo, Alejandro Kuropatwa pone en primerísimo primer plano en su Serie "Coctel", (figura 8) los medicamentos diarios para sobrevivir, hibrida lo sensual y lo mortuorio en las 
March, Natalia Laura

Imágenes del exceso. El neobarroco como forma "invisible" del neoliberalismo político y cultural. Argentina 1990-2000

IV Congreso INTERNACIONAL DE INVESTIGACION EN ARTES VISUALES ANIAV 2019

IMAGEN [N] VISIBLE

http://dx.doi.org/10.4995/ANIAV.2019.9586

imágenes. Bordeando lo indecible con una imagen perfecta, impecable y bella. En primerísimo primer plano, una cuchara de metal que sostiene una capsula de colores brillantes y saturados, no está el cuerpo en si mismo sino como metáfora de lo ausente.

El discurso produce y transporta poder, en un juego complejo, sofisticado e inestable, pero también tiene la posibilidad de obrar como resistencia y generar condiciones para que las estrategias opuestas se ejecuten. En estos casos el cuerpo es sin lugar a dudas el tablero de juego.

\section{CONCLUSIONES}

Luego de este recorrido consideramos que los artistas propusieron el concepto de lo festivo como núcleo coordinante y su exaltación, esto se puso en relación a la liberación de los prejuicios sexuales, a los derechos humanos, a la recuperación del espacio público como lugar de sociabilidad donde se conjugan manifestaciones de alegría y de denuncia

Nos expusieron a los objetos devaluados, los decoraron y los hicieron discretos, para enfrentarnos a nuestras propias imposturas, ya que negamos estos mundos de los cuales nuestra cotidianeidad es parte.

Enfrentaron al espectador a lo aparentemente vacuo, parodiando la vida social, la división clasista entre lo culto y lo popular, asociado a un aparente esteticismo y proponiendo una solapada discusión política. Saturaron las imágenes enfrentándonos a la vida cotidiana desde un posición reflexiva

El cuerpo para ellos fue también cuerpo social, sagrado y evasivo, presentado con una variabilidad extraordinaria de formas. Es un arma que visibiliza reivindicaciones. Son cuerpos amenazantes, que ejercen su función desde una materialidad distinta, e indiferenciada.

Por lo tanto la ambigüedad y la perturbación fueron valores expresado. Recurrieron a tradiciones manuales como labores "femeninas", que reivindicaron sin distinción de sexo. Evidenciando a través de estas estrategias y selección de objetos las complejidades inertes y permitiendo una mirada critica sobre lo socialmente banal.

Cerrando estas ideas que no dejan de ser parciales y acotadas, Calabrese subdivide su libro La era neobarroca, tomando tópicos visibles en las obras; habla de ritmo, repetición, límite, exceso, detalle y fragmento, inestabilidad y metamorfosis, desorden y caos, nudo y laberinto; es notable como se observan estas estrategias en los artistas argentinos.

\section{FUENTES REFERENCIALES}

AAVV, (2013). Algunos artistas. Arte Argentino 1990- hoy. Buenos Aires: Fundación Proa.

Batkis, L. (2005). Latinoamérica. Madrid. Recuperado de http://www.marcoslopez.com/textos-acerca-batkis.php

Calabrese, O. (1999). La era neobarroca. Madrid: Cátedra.

Duprat, A. (2005). Kuropatwa en technicolor. Buenos Aires: Malba/Fundación Costantini.

Echeverría, B. (2002).La clave barroca en América Latina, Quito, julio, p.11. Conferencia realizada en el Latein-Amerika Institut de la Freie Universität ,Berlin, Noviembre.

Espinosa, C. (2012) El barroco y Bolivar Echeverria: encuentros y desencuentros. Íconos. Revista de Ciencias Sociales, 43, pp. 65-80. Quito, mayo.

Giunta, A. (2009). Poscrisis: Arte argentino después del 2001. Buenos Aires: Siglo XXI.

González, V., Jacoby, M. (2009). Cómo el amor. Buenos Aires: Libros del Rojas/CCCEBA.

González, V. (2013). Fotografía argentina 1840-2010. Buenos Aires: Ed. Arte x Arte.

Katzenstein, I., Iglesias, C. (2015). Marcelo Pombo un artista del pueblo. Buenos Aires: Fundación A. Lacroze de Fortabat. 
Imágenes del exceso. El neobarroco como forma "invisible" del neoliberalismo político y cultural. Argentina 1990-2000

IV Congreso INTERNACIONAL DE INVESTIGACION EN ARTES VISUALES ANIAV 2019 IMAGEN [N] VISIBLE

http://dx.doi.org/10.4995/ANIAV.2019.9586

Katzesten, I, Pacheco, M., Cipollini, R., Sato, A. (2006). Pombo. Buenos Aires: Adriana Hidalgo.

Lauria, A. (1999). Arte argentino en los 90: artificio y seducción. Imagen, Boletín del Instituto de Historia del Arte Argentino y Latinoamericano, FF y L, UBA, Año $1, N^{\circ} 1$, noviembre.

Lauria, A. (1996). Juego de damas. Buenos Aires: Centro Cultural Recoleta.

Lauria, A. (2008). Liliana Maresca Transmutaciones. Rosario: Museo Castagnino de Rosario.

Lezama Lima, J. (1993). La expresión americana. México: F.C.E,

López Anaya, J. (1992). El absurdo y la ficción en una muestra notable. La Nación, 1 de agosto. Buenos aires.

López Anaya, J. (2005). Arte Argentino. Cuatro siglos de historia (1600-2000). Buenos Aires: Emecé arte.

Pacheco, M., Crosa, M. R. (2009). Escuelismo. Buenos Aires: Fundación Eduardo F. Costantini-Malba.

Restany, P. (1995). Arte argentino de los 90. Arte guarango para la Argentina de Menem. Lápiz, 13(116), 50-55.

Sarti, G. (2018). Neobarrocos del presente. Vigencia de una categoría estética. Buenos Aires: Arte x Arte.

Sarduy, S. (1987). Ensayos generales sobre el barroco. Mexico-Bs.As. Fondo de Cultura Económica.

Sarduy, S. (2011).El barroco y el neobarroco. Buenos Aires: El cuenco de plata. 
Imágenes del exceso. El neobarroco como forma "invisible" del neoliberalismo político y cultural. Argentina 1990-2000 IV Congreso INTERNACIONAL DE INVESTIGACION EN ARTES VISUALES ANIAV 2019 IMAGEN [N] VISIBLE

http://dx.doi.org/10.4995/ANIAV.2019.9586
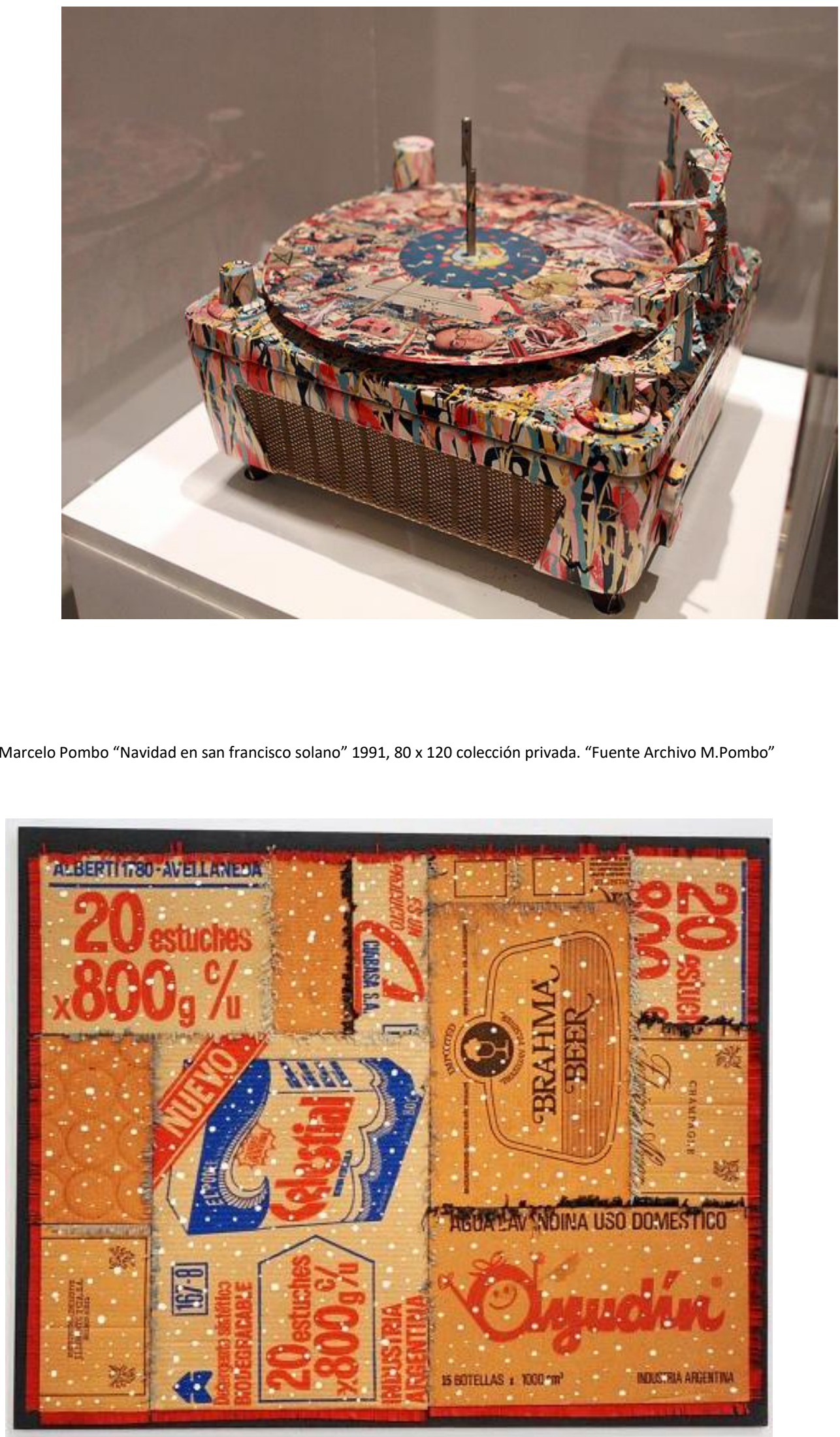

ANIAV Asociación Nacional de Investigación en Artes Visuales 
March, Natalia Laura

Imágenes del exceso. El neobarroco como forma "invisible" del neoliberalismo político y cultural. Argentina 1990-2000 IV Congreso INTERNACIONAL DE INVESTIGACION EN ARTES VISUALES ANIAV 2019 IMAGEN [N] VISIBLE

http://dx.doi.org/10.4995/ANIAV.2019.9586

Figura 3 Omar Schirilo “Sin titulo”, 1991, Recipientes varios de plástico, Medidas variables. “Fuente Archivo J.Gumier Maier”

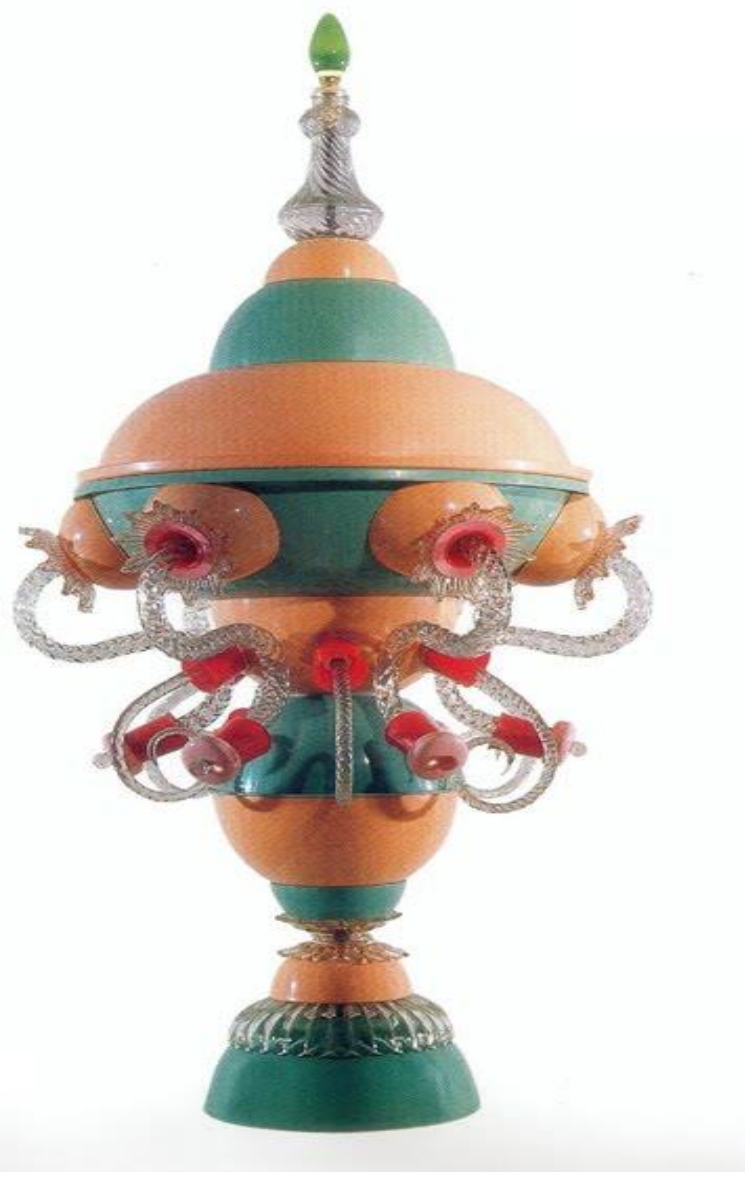

Figura 4 Marcos López, “Carnaval Criollo”, 1997, fotografía. POP LATINO . “Fuente Archivo M.López”

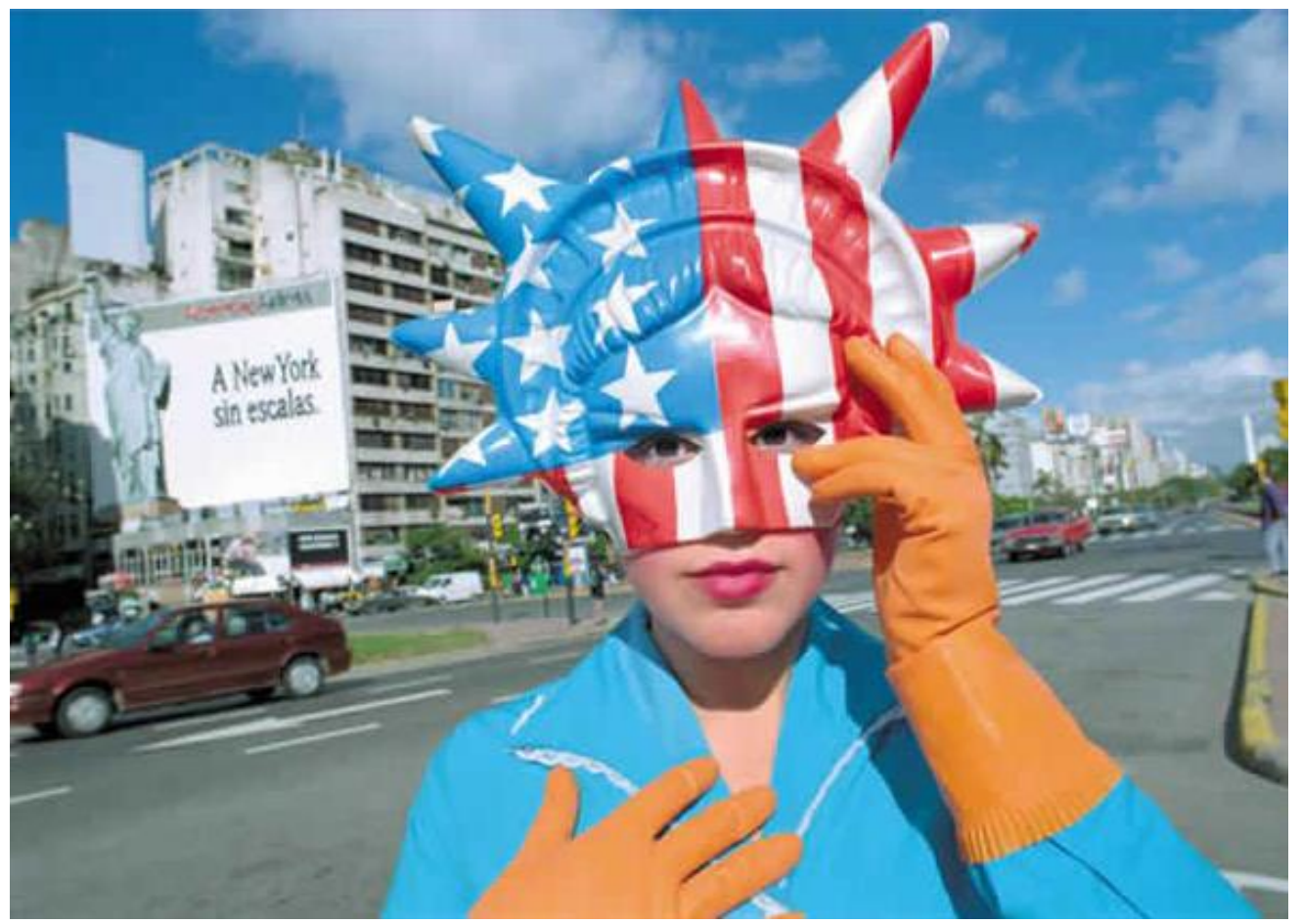

ANIAV Asociación Nacional de Investigación en Artes Visuales

This work is licensed under a Creative Commons Attribution NonCommercial-NoDerivatives 4.0 International License (CC BY-NC-ND 4.0) 
Imágenes del exceso. El neobarroco como forma "invisible" del neoliberalismo político y cultural. Argentina 1990-2000 IV Congreso INTERNACIONAL DE INVESTIGACION EN ARTES VISUALES ANIAV 2019

IMAGEN [N] VISIBLE

http://dx.doi.org/10.4995/ANIAV.2019.9586

Figura 5 Marcos López , "Santuario Bs.As”, 1998 Fotografía, POP LATINO. “Fuente Archivo M.López”

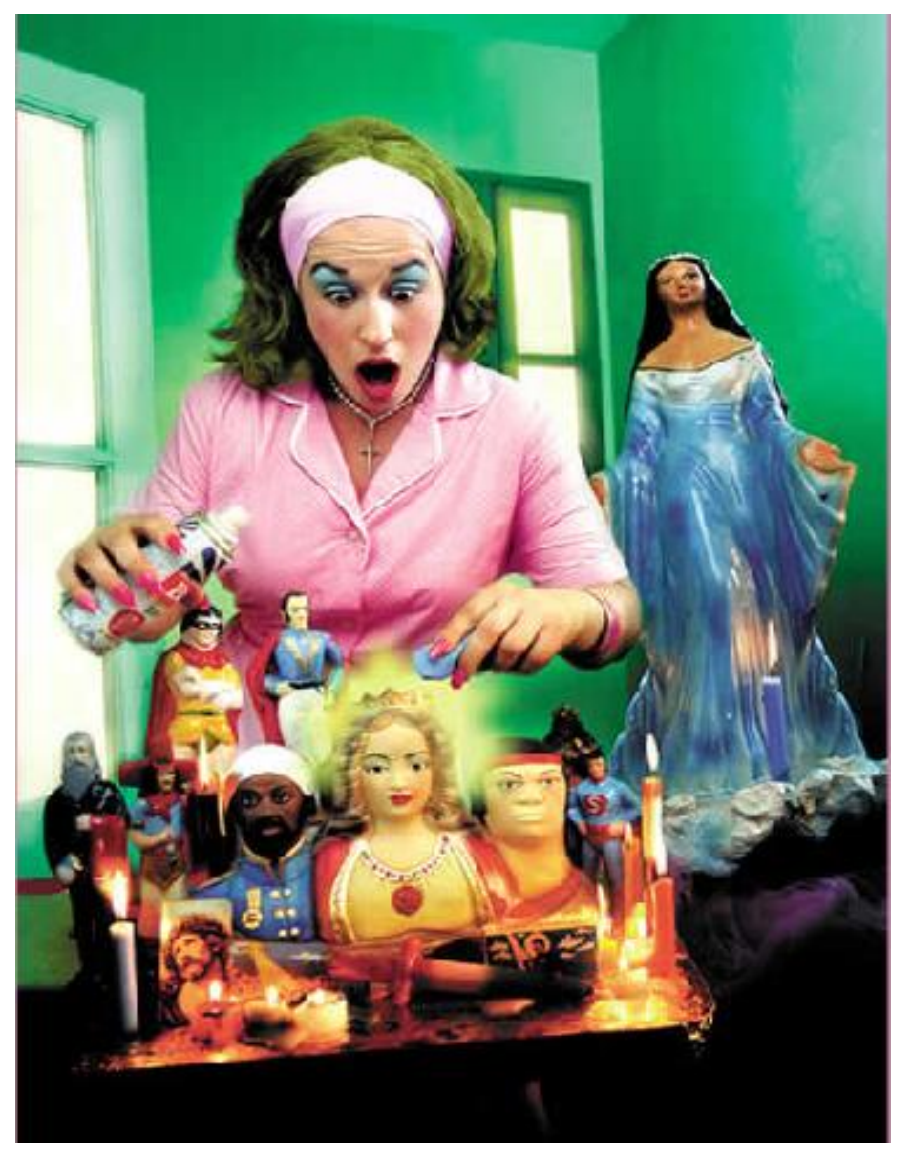

Figura 6 Liliana Maresca. Wotan-Vulcano, 1991, instalación con 8 carcasas de zinc para féretros, alfombra persa, pintura dorada y farol a kerosene, 9 m2. Destruida. "Fuente Archivo Adriana Miranda"

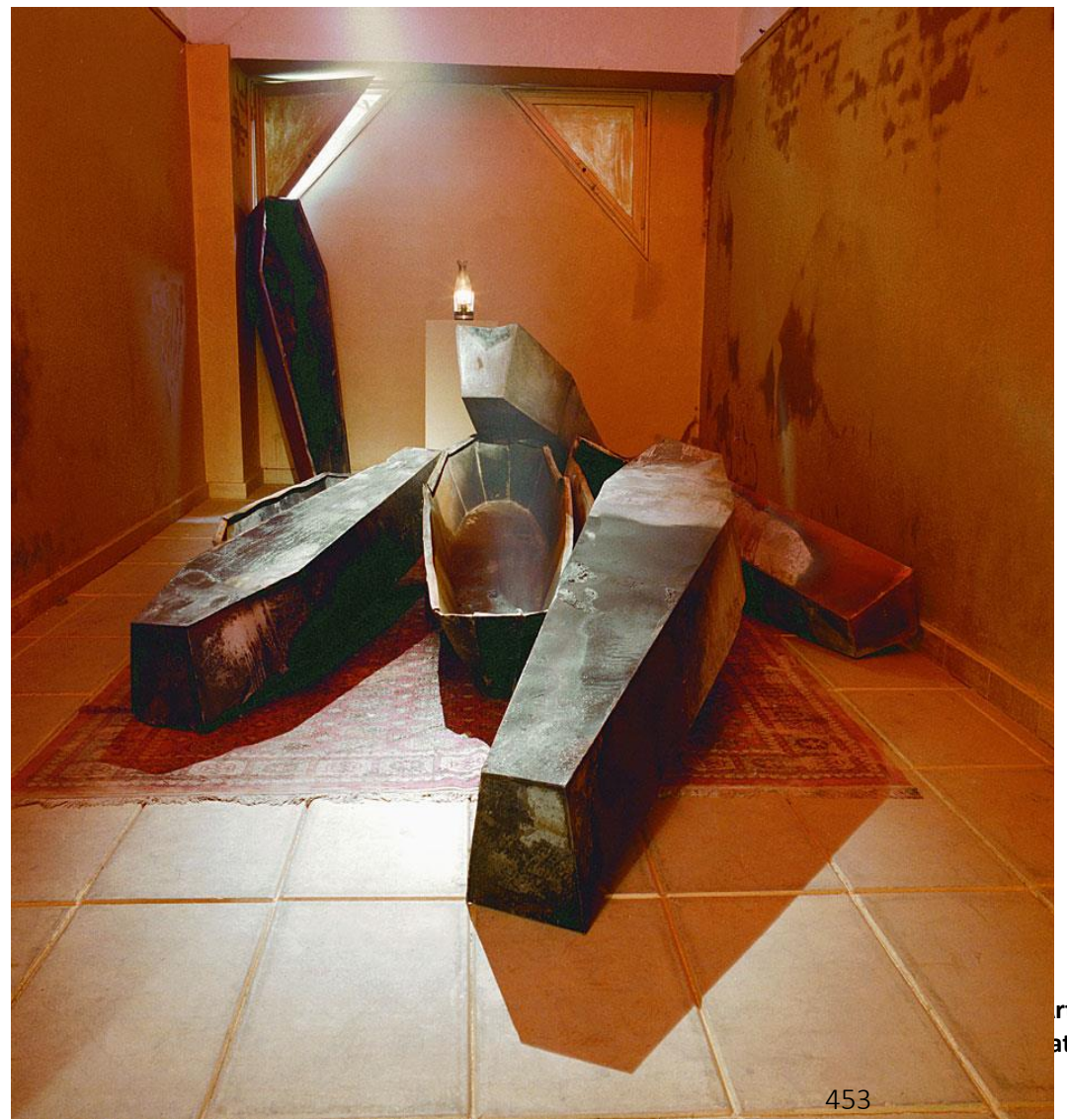


Imágenes del exceso. El neobarroco como forma "invisible" del neoliberalismo político y cultural. Argentina 1990-2000 IV Congreso INTERNACIONAL DE INVESTIGACION EN ARTES VISUALES ANIAV 2019 IMAGEN [N] VISIBLE

http://dx.doi.org/10.4995/ANIAV.2019.9586

Figura 7 Feliciano Centurión, "Me Adapto", 1996, bordado sobre telas. "Fuente Archivo G.Maier"

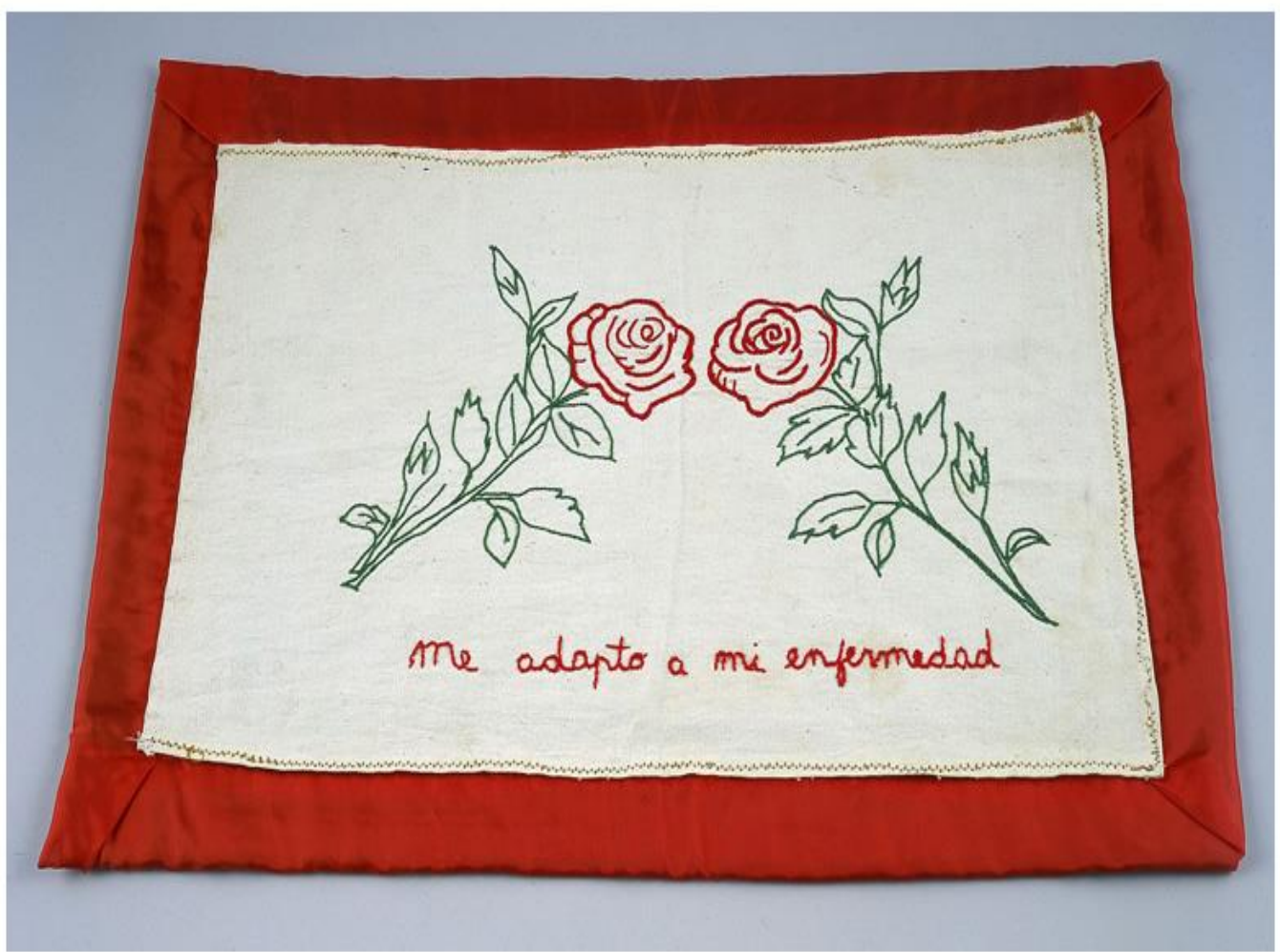

Figura 8 Kuropatwa, Alejandro (1956 - 2003) “Sin titulo " 1996 Fotografía color sobre papel Toma directa 100 x 130 Malba :"Fuente MALBA"

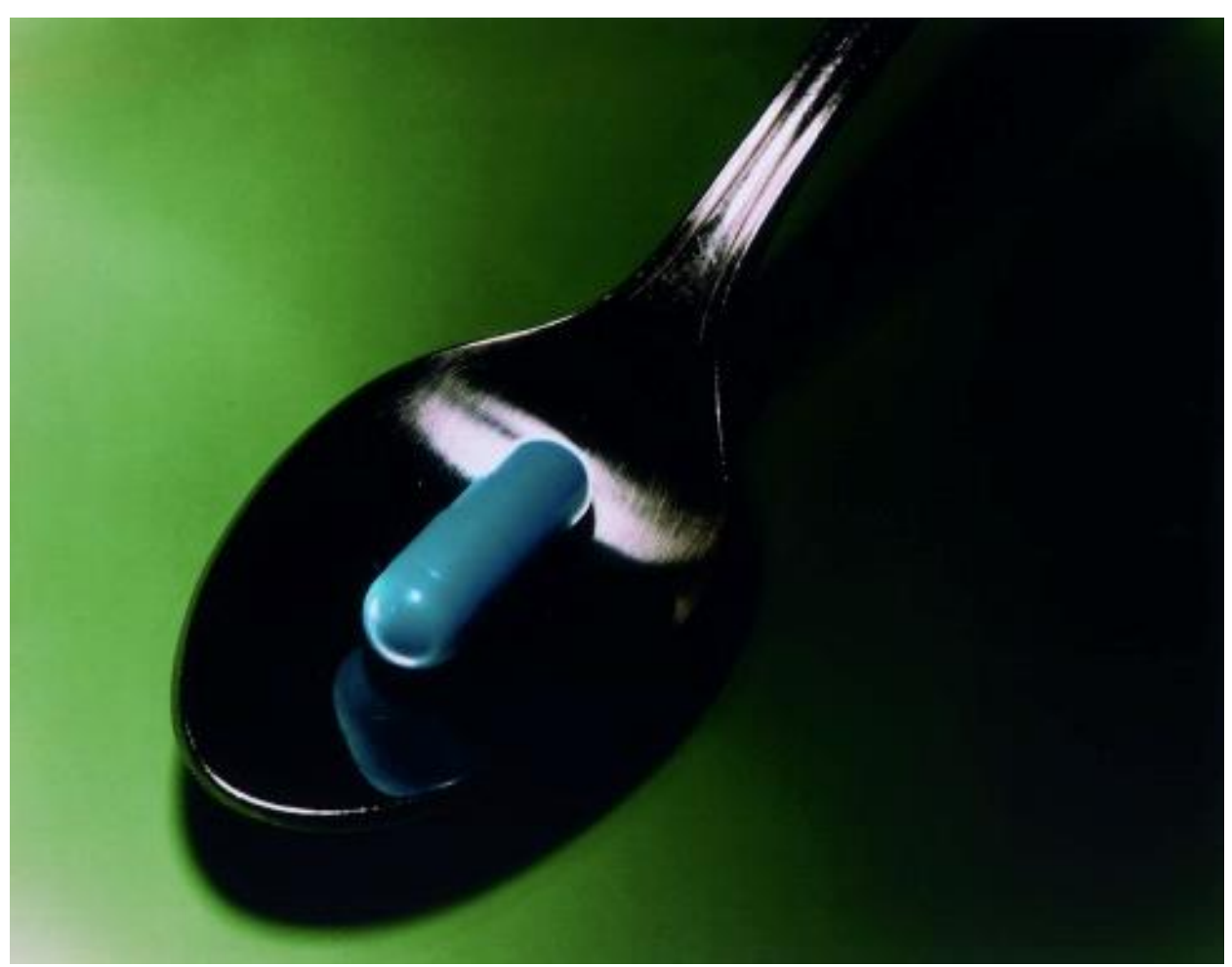

ANIAV Asociación Nacional de Investigación en Artes Visuales 